\title{
Os fragmentos de F. S. Fitzgerald à luz das formas mínimas: uma proposição
}

DOl: http://dx.doi.org/10.21165/el.v49i3.2526

\section{Laysa Louise Silva Beretta ${ }^{1}$}

\section{Resumo}

Considerando a representatividade das narrativas breves no cenário literário contemporâneo, pretendo, à luz das ponderações acerca das formas mínimas (minicontos, mininarrativas, narrativas breves, microcontos etc.), observar os fragmentos escritos por F. S. Fitzgerald e publicados na obra Crack-up (2007) com o intuito de propor algumas possibilidades de leitura. Para tanto, debruçar-me-ei, principalmente, nos trabalhos de Zavala (2004), Gonzaga (2007) e Spalding (2008).

Palavras-chave: formas mínimas; microcontos; F. S. Fitzgerald.

1 Universidade Estadual de Londrina (UEL), Londrina, Paraná, Brasil; laysaberetta@gmail.com; https://orcid.org/0000-0001-8573-5484 


\section{Los fragmentos de F. S. Fitzgerald a la luz de formas mínimas: una propuesta}

\section{Resumen}

Teniendo en cuenta la representatividad de las narraciones cortas en el escenario literario contemporáneo, tengo la intención de, a la luz de las consideraciones acerca de las formas mínimas (minicuentos, mini-narrativas, narraciones cortas, microcuentos etc.), observar los fragmentos escritos por F. S. Fitzgerald y publicados en la obra Crack-up (2007) para proponer algunas posibilidades de lectura. Con ese fin, me centraré, principalmente, en los trabajos de Zavala (2004), Gonzaga (2007) y Spalding (2008).

Palabras clave: formas mínimas; microcuentos; F. S. Fitzgerald.

\section{Introdução}

"Um longo noivado: nada a fazer senão casar ou brigar, por isso decidimos brigar" (F. Scott Fitzgerald)

Nascido nos Estados Unidos, F. Scott Fitzgerald (1896-1940) escreveu romances como This Side of Paradise (Este lado do paraíso, 1920), The Beautiful and the Damned (Os Belos e os Malditos, 1922) e The Great Gatsby (O grande Gatsby, 1925), além ainda de ter publicado contos memoráveis, como "The Curious Case of Benjamin Button" (1922) ("O curioso caso de Benjamin Button", publicado no Brasil em 2008). É hoje considerado um dos maiores escritores americanos, conhecido por narrar e participar de uma geração decadente, formada por jovens obcecados pelo luxo, fama, bebidas e drogas. Nesse sentido, Fitzgerald (2007, p. 5) comenta: "Às vezes não sei se eu e Zelda existimos de fato ou se somos personagens de um romance".

O livro escolhido para este trabalho foi organizado e editado por Edmund Wilson escritor, crítico literário e um dos amigos mais importantes de Fitzgerald. Trata-se de uma publicação póstuma, que reúne alguns ensaios autobiográficos - incluindo "Crack-up", que dá nome ao livro -, cadernos de notas do autor, cartas e outros ensaios. Interessa-me os cadernos de notas. No livro, a seção dedicada aos cadernos é dividida por um sumário que vai da letra "A" até a letra "U". Há, por exemplo, o caderno dedicado às "Anedotas" (A), aos "Brilhantes recortes" (B), aos "Epigramas, gracejos e piadas" (E), às "Ideias" (I), ao "Literário" (L), às "Observações" (O) e aos "Títulos" (T).

O número de textos retirados dos cadernos de notas é extenso. Metade do livro (de aproximadamente trezentos e setenta páginas) é ocupado pela seção. Os textos ali elencados, entretanto, são breves: a maioria não ultrapassa um terço de página. Com 
exceção daqueles presentes no caderno de títulos, que não ultrapassam o caráter de possíveis títulos a obras e algumas listas esparsas dedicadas a temas como gírias correntes, nomes interioranos e viagens desagradáveis, os cadernos comportam fragmentos, pequenos textos em potência, talvez embriões para possíveis narrativas de maior fôlego. A ideia de que os fragmentos foram parte do processo de criação do autor não parte dos textos em si, até porque a maioria ${ }^{2}$ deles pode ser lida e compreendida como textos acabados sem prejuízo algum (o que nos remete à noção de fractalidade proposta por Zavala, 2004), mas do fato de que as notas, em conjunto, assemelham-se a um compêndio literário para uso pessoal desde as listas mencionadas até os diálogos, as máximas e as analogias ali presentes. Sem contar que os assuntos abordados não fogem ao estilo literário empenhado por Fitzgerald em obras maiores e anteriores.

O que salta aos olhos, sem mencionar a qualidade, é a brevidade e a precisão dos textos. À luz das discussões acerca do texto breve, parece-me possível aventar alguns parentescos entre os pequenos textos de Fitzgerald e o que chamamos hoje de mininarrativas. Além da possibilidade de considerar os fragmentos como pequenas narrativas em potência e de salientar o protagonismo do leitor (SPALDING, 2008) frente ao texto, destaco algumas frequentes em comum: o humor, o chiste, os aforismos, as anedotas, as máximas e o tom proverbial.

Não pretendo, é claro, afırmar que se tratam de mini ou microcontos, até porque as classificações importam pouco e, como pontuou Mário de Andrade, "conto será sempre aquilo que o seu autor batizou de conto". Tampouco pretendo encerrar, em uma análise de curto fôlego, a discussão sobre a proximidade sugerida. Assim, a intenção desta breve pesquisa, além de lançar luz sobre os brilhantes textos de Fitzgerald (completamente ignorados com relação aos ensaios presentes na primeira seção), éapontar para a seguinte proposição: é possível, a partir do que compreendemos sobre os textos breves, relacionar os fragmentos de Fitzgerald à mininarrativa? A proposição não visa a classificação dos textos do autor norte-americano, o intento é indicar novas possibilidades de leitura. Por exemplo, de que forma o parentesco soma à leitura dos textos de Fitzgerald e ao que se pondera acerca das mininarrativas?

2 Convém ressaltar a presença de alguns comentários e trechos que poderiam ser lidos como propostas criativas para textos literários. Exemplos: "Embora cuidadoso para evitar os clichês no seu trabalho, Ernest Hemingway se delicia com eles na vida privada, sendo o seu favorito 'Parbleu' ('E daí?', em francês) e 'Sim, não temos bananas'. Ao contrário da opinião popular, ele não é tão alto quanto Thomas Wolfe, tendo apenas um metro e noventa e cinco no seu colete terapêutico. É naturalmente desajeitado com o seu corpo, mas visto de um anteparo ou de uma cobertura adequada, revelava-se uma bela figura de homem. Temos a satisfação de anunciar que a sua obra aparecerá no futuro exclusivamente em selos do correio dos Estados Unidos" (FITZGERALD, 2007, p. 204). "Quase um capítulo inteiro sobre a tentativa de o homem educar os filhos sem saber onde ele próprio se encontra - entre dificuldades" (2007, p. 239). 


\title{
Formas mínimas ${ }^{3}:$ a totalidade da brevidade (ou vice-versa)
}

\author{
"Estou com pressa." \\ "Estou com pressa, estou com pressa." \\ "Por que você está com tanta pressa?" \\ "Não posso explicar: estou com pressa". (F.S. Fitzgerald)
}

Em 1985, Ítalo Calvino elencava seis propostas para o próximo milênio: leveza, rapidez, exatidão, visibilidade, multiplicidade e consistência. A última proposta não chegou a ser escrita. Como sabemos, o autor faleceu antes de elaborar o seu conteúdo. De qualquer forma, não é tarefa árdua para o leitor aventar o que pretendia Calvino ao considerar a consistência, principalmente se levarmos em conta o que o autor pondera nas cinco propostas anteriores.

A partir de inúmeras referências literárias, Calvino sugere, entre outros pontos, a omissão de detalhes em prol de uma estrutura narrativa fluida, rápida e eficaz, um projeto narrativo estruturado e calculado, a evocação de imagens nítidas e memoráveis, o esforço com as palavras para que seja possível cuidar, com precisão, do aspecto sensível das coisas e afirma que "os livros modernos nascem da confluência e do entrechoque de uma multiplicidade de métodos interpretativos, maneiras de pensar, estilos de expressão" (CALVINO, 1997, p. 131).

Retomo Calvino para pensar nas narrativas breves, um gênero, ou melhor, um mini gênero que sozinho contemplou várias, se não todas, as propostas deixadas pelo autor e crítico italiano, além de ser uma presença difícil de ignorar no novo milênio: microfiction, short short story e very short story para os norte-americanos, minicuento, ficción mínima e minificción para os hispânicos e miniconto, mininarrativa, microconto e microficção em língua portuguesa.

É difícil precisar a origem dessas formas narrativas mínimas ou breves, já que é possível pensar e considerar como minificção as fábulas chinesas e alguns aforismos de Franz Kafka. Ernest Hemingway foi autor de um célebre microconto ("For sale: baby shoes, never worn") e os breves capítulos escritos por Machado de Assis em Memórias Póstumas de Brás Cubas (1881), além ainda do conto "Um apólogo" (Várias Histórias, 1886), são também considerados exemplos de concisão literária.

3 Detenho-me no termo cunhado por Miguel H. Braga Vieira para não selecionar uma das inúmeras designações ou classificações possíveis (miniconto, mininarrativa, minificção, microcontos, micronarrativas etc.) e incorrer no erro de desconsiderar o caráter hibrido dos textos breves e dos fragmentos de Fitzgerald. 
De qualquer forma, o posto de principal e mais exemplar minificção é do guatemalteco Augusto Monterroso que, em 1959, publicou a seguinte narrativa: "Cuando despertó, el dinosaurio todavía estaba allı" (grifo nosso). O posto não se deve apenas ao pioneirismo da criação, mas, sobretudo, porque o autor "fez do conto breve uma poesia narrativa potente e atravessada por lances de humor" (SCHØLLHAMMER, 2009, p. 94).

No Brasil, apesar de registros anteriores (Machado de Assis, Raul Pompéia e alguns modernistas), a obra Ah, é? (1994, Editora Record), de Dalton Trevisan, é considerada a primeira obra de minicontos 4 . Seguida pelos textos de Marina Colasanti, Ivana Arruda Leite, Verônica Stigger, Fernando Bonassi, João Gilberto Noll, Luiz Vilela, Marcelino Freire e outros. Marcelino Freire, inclusive, promoveu e organizou o volume Os cem menores contos brasileiros do século (2004). No prefácio da organização, Freire esclarece: "Resolvi desafiar cem escritores brasileiros, deste século, a me enviar histórias inéditas de até cinquenta letras (sem contar título, pontuação). Eles toparam. O resultado aqui está. Se 'conto vence por nocaute', como dizia Cortázar, então toma lá" (FREIRE, 2004, n.p).

A antologia representa, sem dúvida, uma importante referência para a minificção brasileira. A proposta feita pelo autor pernambucano foi acatada por autores como Marçal Aquino, João Paulo Cuenca, Antonio Prata, Antônio Torres, Luiz Rufatto e Fabrício Carpinejar. Além ainda de ser prefaciada por Ítalo Moriconi, organizador de Os cem melhores contos brasileiros do século (Editora Objetiva).

Imagens como estalo, instante ou gatilho são providenciais para considerar a brevidade desses textos. As ponderações acerca do conto - não apenas do conto breve - parecem ser empenhadas com ainda mais vigor quando pensamos nas mininarrativas. A ideia de Cortázar levantada por Marcelino Freire no prefácio da organização mencionada, por exemplo, argumenta que, no embate travado entre um grande texto e o seu leitor, o conto, diferentemente do romance que ganha por pontos, vence por nocaute. Quer dizer, o conto não se utiliza de imagens ou elementos gratuitos, pois sabe que o tempo não é seu aliado. Cortázar afirma, no texto "Alguns aspectos do conto", que "o seu único recurso é trabalhar em profundidade" (CORTÁZAR, 1993, p. 152).

Nesse mesmo sentido, Hemingway sugere a Teoria do Iceberg - buscando o máximo (de sentido) a partir do mínimo (aparente no texto) -, Anton Tchékhov a Teoria do "fuzil" e

4 Existem algumas definições (um pouco arbitrárias, é preciso dizer) com relação à minificção e ao número de caracteres empenhados. Fala-se, assim, em miniconto, minificção, mininarrativa, microconto, nanoconto ou nanoficção etc. Entretanto, não cabe, durante esta pequena análise, lançar mão de tais definições e/ou enquadrar as narrativas nas especificações mencionadas. Desse modo, lidarei, quase indistintamente, com os termos "minicontos", "mininarrativas" ou "minificção" porque contemplam textos de tamanhos moderados e abarcam também os textos de brevíssimas extensões (micro e nano). 
Dalton Trevisan o pico na veia. São, é claro, analogias e imagens para a produção literária contística. A ideia de pico na veia está, inclusive, em um conto de Trevisan que diz "Um bom conto é como um pico certeiro na veia" (TREVISAN, 2002, p. 9).

A concisão, a brevidade e a unidade de impressão (POE) pretendidas no conto são potencializadas quando pensamos no miniconto. O gênero conto é desdobrado e, assim como afirma Antonio Candido (1989, p. 208), incorpora "técnicas e linguagens nunca dantes imaginadas dentro de suas fronteiras".

Além da reduzidíssima extensão textual - produto de um depuramento textual voltado para a concisão e de uma relação com a estética minimalista -, as narrativas breves aproximam-se, não raras as vezes, da piada, do jogo de palavras, das anedotas, dos provérbios invertidos ou parodiados, dos epigramas, dos aforismos e de retratos do cotidiano.

Nesse sentido, Miguel Heitor Braga Vieira (2012, p. 146) pondera:

Chegamos a dez tipos formais de minificção: 1) o miniconto, 2) a minifiç̧ão proverbial ou aforística, 3) a com feição de piada ou jogo de palavras, 4) a com marcas fabulares e modais, 5) a minicrônica, 6) a minificção com diç̧ão poética, 7) a intertextual ou de aproximação, 8) a metalinguística ou metaminificção, 9) a ensaística e 10) a minificção gráfica. Distantes de qualquer normatização formal e rigidez classificatória, tratamos de apontar constantes formais da minificção, atentando para suas relações internas.

O excerto exposto não é mencionado com o intuito de estabelecer uma categoria ou uma classificação para as formas mínimas, mas para observar brevemente, na esteira de Vieira, as constantes, a rede de influências e relações presentes no gênero e, então, as suas heranças e/ou inovações técnicas e textuais com relação ao conto. Quer dizer, é uma possibilidade de expandir a certeza acerca da brevidade e da precisão linguística, e conhecer os caminhos trilhados pela minificção, algo que talvez contribua com a compreensão dos traços e do impacto desses pequenos textos nas últimas décadas.

Nesse sentido, convém dizer que as narrativas breves cabem em todo lugar: no livro impresso, no Facebook, no Twitter, em SMS e em caixas de fósforo ${ }^{5}$. Valem muito mais pelo que não está escrito, são como imagens e há, ao menos, duas narrativas ali - o que explica o papel primordial do leitor no processo interpretativo. Sobre a acessibilidade,

5 Samir Mesquita organizou e publicou, em 2007, o projeto e livro Dois Palitos. A publicação consiste em vários folhetos pequenos dentro de uma caixa de fósforos, cada folheto continha um microconto. 
arrisco dizer que o formato é mais democrático, já que não se trata de um texto escrito com pretensões ao cânone, ainda que aclamado pela crítica. A qualidade não é medida pelo rebuscamento ou requinte, mas pelo nocaute empenhado pelo texto, e a simplicidade com relação ao processo de escrita é apenas aparente, pois a cobiçada brevidade é alcançada a partir de um depuramento textual intenso mencionado por autores como Marcelino Freire, Andréa Del Fuego e Dalton Trevisan. O último, inclusive, pontuou: "para escrever o menor dos contos a vida inteira é curta" (TREVISAN apud WALDMAN, 1997, p. 142).

Por fim, encerro esta breve apreciação ao miniconto ou texto breve com o que pondera Italo Moriconi ao prefaciar a obra Os cem menores contos do século (2004, n.p.): "É no lance do estalo que a cena toda se cria. Na narrativa e na poesia. Alguém já disse, poesia é uma frase ou duas e uma paisagem inteira por trás. Neste volume, a prova: conto também, em número de cem. São pílulas ficcionais, e das melhores".

\section{Fitzgerald e as suas pequenas histórias em potência}

"Ouça, pequeno Elia: puxe sua cadeira para perto do precipício e eu Ihe contarei uma história" (F. S. Fitzgerald).

Para traçar o parentesco sugerido, parece-me necessário recorrer às principais compreensões teóricas com relação à mininarrativa e, então, articulá-las aos fragmentos de F. S. Fitzgerald. Dessa forma, volto-me, a seguir, para as asserções do mexicano Lauro Zavala em Cartografias del cuento y la minificción (2004), de Pedro Gonzaga, na dissertação A poética da minificção: Dalton Trevisan e as minihistórias de Ah, é? (2007), de Marcelo Spalding e na dissertação Os cem menores contos do século e a reinvenção do miniconto na literatura brasileira contemporânea (2008).

O mexicano Lauro Zavala é professor da Universidad Autónoma Metropolitana de Xochimilco e publicou, além de Cartografias del cuento y la minificción (2004), El dinosaurio anotado: edición crítica de "El dinosaurio" de Augusto Monterroso (2002), Laminificción en México: 50 textos breves (2002) e La minificción bajo el microscópio (2005) e Cómo estudiar el cuento: con una guía para analizar minificción y cine (2002). Sem contar, é claro, publicações dedicadas a temas como literatura contemporânea, teoria literária e cinema.

A posição de Zavala é, de modo geral, bastante conservadora. O professor busca lidar com classificações bastante engessadas, como enquadrar categoricamente os textos com relação ao número de caracteres ${ }^{6}$ e segmentar os minitextos em três categorias:

6 "Empezaré por responder a la pregunta: ¿cuántos tipos de cuentos breves existen?, pues ésta es la pregunta fundamental y es la que permite responder las demás preguntas. Para estudiar el 
"minicuento (clássico)", "micro-relato (moderno)" e "minificción (posmoderna)" (ZAVALA, 2011).

Todavia, Zavala destaca, em Cartografias del cuento y la minificción (2004), seis pontos fundamentais à minificção e bastante esclarecedores se articulados aos textos de Fitzgerald. São eles: 1) brevidade, 2) diversidade 3) cumplicidade, 4) fractalidade, 5) fugacidade e 6) virtualidade (ZAVALA, 2004, tradução nossa7).

Com exceção da virtualidade - que indica a importância dos aportes digitais para a minifıcção - e da cumplicidade - que aponta para o vínculo estabelecido entre o leitor e o texto a partir do título da narrativa -, os pontos propostos por Zavala são perfeitamente praticáveis quando pensamos no parentesco sugerido neste trabalho.

Nesse sentido, tomemos como objeto de análise os seguintes fragmentos de Fitzgerald:

"Agora é tudo tão inútil quanto repetir um sonho" (FITZGERALG, 2007, p. 105).

"'Meu último marido foi derrubado do cavalo. Você deve aprender a montar'. Ele dá uma olhada inquieta ao redor à procura de um cavalo" (FITZGERALG, 2007, p. 106).

Ao ponderar sobre a brevidade, Zavala demarca a proximidade com a tradição oral, o valor didático de pequenas narrativas, o crescente entusiasmo frente ao gênero e afirma que 0 espaço de uma página - muitas vezes, apenas parte de uma página - pode "alcançar a maior complexidade literária, a maior capacidade de evocação e a dissolução do projeto romântico da cultura" (ZAVALA, 2004, p. 71, tradução nossa8).

O entusiasmo de Zavala diante da brevidade das mininarrativas é algo a ser observado. Os textos, precisos e potentes, são considerados como uma promessa literária e cultural. Não julgo conveniente transmitir a euforia do pesquisador aos textos de Fitzgerald, mas

cuento breve podemos partir del acuerdo que existe entre escritores y críticos al señalar que la extensión de un cuento convencional oscila entre las 2.000 y las 10.000 palabras. Al estudiar las antologías y las investigaciones que se han realizado hasta ahora sobre cuentos cuya extensión es menor a las 2.000 palabras, en lo que sigue propongo reconocer la existencia de tres tipos de cuentos breves. Las diferencias genéricas que existen entre cada uno de estos tipos de cuentos dependen de la extensión respectiva. Aquí propongo llamar a cada uno de estos tipos de relatos, respectivamente, cuento corto, muy corto y ultracorto. Por debajo del límite de las 2.000 palabras parece haber tres tipos de cuento distintos entre sí: cortos (de 1.000 a 2.000 palabras), muy cortos (de 200 a 1.000 palabras) y ultracortos (de 1 a 200 palabras)" (ZAVALA, 2002, p. 240, grifo nosso).

7 No original: "1) brevedad, 2) diversidad, 3) complicidad, 4) fractalidad, 5) fugacidad e 6) virtualidad".

8 No original: "Para lograr la mayor complejidad literaria, la mayor capacidad de evocación y la disolución del proyecto romántico de la cultura". 
acredito que o primeiro texto citado pode ser analisado a partir da brevidade asseverada por Zavala.

O texto conta com apenas nove palavras e, ainda que não seja o responsável por promover a "dissolução do projeto romântico da cultura" (FITZGERALG, 2017, p. 71) alcança, sem nenhuma dúvida, alguma complexidade literária. Trata-se de uma comparação prosaica, mas precisa e potente. Precisa na criação de uma imagem e potente ao manejar, em poucas palavras, uma percepção outra - e bastante sensível - acerca da inutilidade. O termo "inútil", geralmente ligado à banalidade, é deslocado e aproximado do que é sublime e ingênuo: o sonho, a esperança. Tudo tão inútil quanto repetir um sonho, tudo tão inútil quanto sonhar de novo, tão inútil quanto tentar outra vez, tão inútil quanto não desistir. O "agora" acrescenta também, pois não só situa temporalmente o discurso, colaborando com o caráter sensível destacado, como também convida o leitor ao texto, tornando possíveis indagações como "Por que agora?", "O que tornou tudo inútil a partir daquele momento?" ou "O que o agora representa?". Assim, não posso deixar de observar: tudo isso em apenas nove palavras.

Ainda nessa direção, é válido observar o segundo texto de Fitzgerald e analisá-lo à luz das proposições de Zavala sobre a diversidade, a fugacidade e a fractalidade.

No que tange à diversidade, Zavala assinala, principalmente, o caráter hibrido (não apenas com relação à estrutura) das minificções. Reconhece-se, assim, a diversidade de gêneros que se aproximam dos textos breves, a consequente abertura de realização e a influência das fábulas, dos bestiários e das histórias fantásticas.

No ponto dedicado à fugacidade, Zavala discute a dimensão estética da minificção. Trata-se de um pressuposto ligeiramente complexo, porque não aponta para uma saída definitiva, mas para abordagens. Vale esclarecer, de antemão, que as assertivas do pesquisador sobre a diversidade e fugacidade são complementares na medida em que a ideia, em fugacidade, é discutir a literariedade, o alcance, a classificação e a durabilidade desses textos, principalmente os marcadamente híbridos. $\mathrm{O}$ anseio, bastante antigo, por definições: são contos? Ou ainda: são literatura? Assim, para justificar a durabilidade e relevância literária das mininarrativas, Zavala elenca uma porção de periódicos, eventos, antologias e concursos dedicados ao assunto.

No ponto dedicado à fractalidade, Zavala propõe um contraponto interessante - e muito caro aos textos de Fitzgerald - entre fragmento e unidade. O pesquisador mexicano entende como fractalidade a independência de um texto com relação à unidade que o contém e sugere que essa é a forma de leitura do final do século XX. Afırma que saltar páginas, ler qualquer coisa e picotear são direitos do leitor. Ainda nesse sentido, assevera que a ideia trazida por um fragmento não é um detalhe, mas um elemento que contém uma totalidade que merece ser descoberta e explorada por si só (ZAVALA, 2004). 
A noção estabelecida em torno do conceito de fractalidade é providencial não só para a análise do segundo minitexto citado, pois a tensão entre a ideia de fragmento e unidade é evocada de modo ininterrupto durante a leitura9 ${ }^{9}$ do caderno de notas. Retomemos:

"'Meu último marido foi derrubado do cavalo. Você deve aprender a montar'. Ele dá uma olhada inquieta ao redor à procura de um cavalo" (FITZGERALG, 2007, p. 106).

É completamente possível pensar no texto como fragmento, peça constituinte de um contexto ou narrativa maior, mas não é possível ignorar que o fragmento pode e deve ser lido e compreendido por si só, como uma unidade de sentido autônoma. É igualmente impensável ignorar que o texto, em tão poucas palavras, lança mão do humor, apresenta duas histórias (PIGLIA, 2004) - uma de compreensão literal ou aparente e outra de assimilação oculta - e convida o leitor, como toda boa mininarrativa, ao texto, para protagonizar a interação promovida no processo de leitura.

É ainda importante mencionar que a fractalidade ou a valorização do estilhaço como portador de uma unidade de sentido pode somar muito à leitura dos textos de Fitzgerald, que são, como já dissemos anteriormente, diminuídos ao caráter de notas esparsas e ignorados com relação aos ensaios publicados no mesmo volume. Assim, se considerarmos a fractalidade, os fragmentos deixam de ser notas ou excertos não desenvolvidos para tornarem-se pequenas histórias em potência.

O minitexto pode ainda ser articulado às noções de diversidade e fugacidade se considerarmos a proximidade do diálogo com a piada, por exemplo, e de que forma essa proximidade dificulta uma definição precisa em torno do gênero (é um conto?) e da literariedade (trata-se de literatura?) do texto. O hibridismo - bastante observado e discutido - assinalado nas mininarrativas percorre também todo o caderno de notas de F. S. Fitzgerald. Os textos se aproximam de poemas, canções, provérbios e, principalmente, piadas.

Abaixo, textos que se aproximam do provérbio e da piada, respectivamente:

Provérbio egípcio:

As piores coisas:

Estar na cama e não dormir,

Querer alguém que não vem,

Tentar agradar e desagradar (FITZGERALG, 2007, p. 99).

9 Outro exemplo possível: "Ele quer fazer de mim uma deusa, e eu quero ser Mickey Mouse" (FITZGERALD, 2007, p. 106). 
O início de uma história, Incorrigible.

Pai: A quem você admira?

Filho: Andy Gump. Quem você acha que admiro - George Washington? Cresça e apareça! (FITZGERALG, 2007, p. 101).

Nesse sentido, é importante dizer que o caráter proteico das minificções provoca perguntas relacionadas à dimensão estética dos textos. Evidentemente, a saída para essas perguntas não é simples. Zavala, inclusive, indica como resposta a atenção que a minificção tem recebido nas últimas décadas. Não acredito que a justificativa seja insuficiente, acredito apenas que se trata de uma preocupação incoerente, principalmente se considerarmos a atestada fluidez dos gêneros literários na pós-modernidade. Além disso, parece-me injusto propor classificações engessadas a textos que sugerem inúmeras possibilidades de leitura.

Pouco importa se os textos de Fitzgerald, por exemplo, são notas, fragmentos, excertos ou mininarrativas. Os textos valem pelo alcance, pela potência e, principalmente, pelos efeitos que promovem durante a leitura, não pelas possibilidades viáveis para a criação de um cânone.

Prosseguindo com a articulação proposta, recorro agora às contribuições de Pedro Gonzaga, escritor e pesquisador brasileiro do Rio Grande do Sul que publicou a dissertação A poética da minificção: Dalton Trevisan e as minihistórias de Ah, é? Na pesquisa, Gonzaga discute e trabalha metodologicamente com o conceito de minificção, propondo divisões (divisão formal e poética) e apontando características frequentes independentes do potencial narrativo, como "brevidade extrema, intertextualidade e ironia" (GONZAGA, 2007, p. 37). Interessa-me, entretanto, articular o que Gonzaga afirma sobre a mínima unidade narrante aos minitextos de Fitzgerald. Para Gonzaga, unidades mínimas narrantes são as estruturas mínimas de um miniconto. De acordo com ele, ainda que cada frase em separado contenha um valor enquanto ação, "o narrante só é compreendido dentro da ação completa" (GONZAGA, 2007, p. 48). É possível tomar como exemplo de mínima unidade narrante a storyline do romancista inglês Graham Greene: "Fui ao enterro de um amigo. Três dias depois, ele passeava pelas ruas de Nova York", e um conto completo como máxima unidade narrante.

Gonzaga ainda adverte que a mínima unidade narrante não garante um miniconto, mas que para que um miniconto ocorra, a mínima unidade narrante é indispensável. Nesse sentido, vale dizer que a abordagem de Gonzaga é bastante conservadora ao ignorar outros tipos de minificção, como textos que estariam mais próximos da poesia, do aforismo e da paródia. 
Ainda que não seja uma das minhas pretensões considerar mecanismos definidores tão específicos (relacionados apenas ao miniconto, deixando de lado publicações marcadamente híbridas) para aplicá-los aos textos de Fitzgerald, vale demonstrar que os fragmentos presentes nos cadernos de notas respondem até mesmo às abordagens mais rígidas.

Assim, proponho a leitura de três textos:

O pai ensina o filho a jogar na máquina adulterada; mais tarde, o filho inconscientemente perde a garota nesse jogo. (FITZGERALD, 2007, p. 165).

Eles foram dormir tranquilamente com a dor de outras pessoas. (FITZGERALD, 2007, p. 158).

Ela escalou uma rede de aço, concreto e vidro, caminhou sob um domo alto que ecoava e saiu em Nova York. (FITZGERALD, 2007, p. 124).

Ouso dizer que os três minitextos de Fitzgerald estão compostos de ao menos uma unidade mínima narrante. São, para Gonzaga, minicontos, pois mantêm a característica básica e definidora de uma narrativa. É pertinente afirmar, entretanto, que textos como os expostos acima são minoria nos cadernos de notas de Fitzgerald, quer dizer, ainda que alguns respondam ao rígido parâmetro estabelecido pelo pesquisador, a maior parte dos fragmentos é marcada pelo hibridismo. Esse fato nos permite dizer, a partir das proposições de Gonzaga, que a maioria dos textos do autor norte-americano não corresponde à categoria de miniconto, mas à categoria de minificção. De qualquer forma, acredito piamente na desimportância de tal classificação e, por isso, sigo referindo-me aos fragmentos como minitextos.

Marcelo Spalding, um escritor e jornalista brasileiro, defendeu, em 2008, uma dissertação que se voltou para as especificidades do miniconto e para a publicação de Os cem menores contos brasileiros do século, organizada pelo escritor Marcelino Freire. No trabalho, Spalding procura refletir sobre a presença do miniconto no Brasil, além ainda de discorrer acerca do impacto provocado pela antologia já mencionada. De acordo com ele, a reunião promovida por Marcelino Freire é responsável pela reinvenção do miniconto no Brasil. No que tange ao seu trabalho, concentro-me, por fim, no que pondera Spalding a respeito do protagonismo do leitor.

Adiantei, ainda que brevemente, a relação entre leitor e mininarrativa em outros momentos do trabalho. Spalding aponta justamente para essa relação quando afırma que o miniconto "intensifica a importância do não dito na narrativa, diminui o volume do iceberg acima da superfície de um oitavo para, digamos, vinte anos, sem impedir, se o texto estiver bem realizado, que ele suscite certo efeito" (SPALDING, 2008, p. 62). 
Grosso modo, a ideia é que, ao diminuir o tamanho do iceberg acima da superfície, o autor convida o leitor à narrativa, exigindo dele maior compreensão e interação.

Deliberado ou não, os fragmentos de Fitzgerald convidam o leitor ao texto e estabelecem, em poucas palavras, ao menos duas histórias: "Não temos mais gim', disse ele. 'Você aceita um calmante?', acrescentou esperançoso" (FITZGERALD, 2007, p. 104).

O pequeno fragmento acima, presente no caderno "Conversas e coisas escutadas por acaso", reproduz um pequeno diálogo. A história visível (ou a ponta do iceberg) apresenta uma resposta a alguém que pede por um copo de gim. O visível, entretanto, não é suficiente e o leitor, naturalmente, elabora algumas possibilidades para lidar com os silêncios do texto. É possível indagar: quem serve? Quem pede pelo drink? Um garçom? Mas por que o garçom oferece um calmante? O que ele percebeu? Teria essa intimidade? Por que ele tem esperanças de que a pessoa aceite? O que ele ganharia com isso?

O leitor pode apresentar conduta semelhante diante do texto seguinte: "'Meu último marido foi derrubado do cavalo. Você deve aprender a montar'. Ele dá uma olhada inquieta ao redor à procura de um cavalo" (FITZGERALD, 2007, p. 106).

O fragmento acima também compõe o caderno "Conversas e coisas escutadas por acaso". Diante dele, o leitor tem a história aparente: alguém justifica ao novo marido ou namorado o porquê de ele precisar aprender a montar, mas o homem, ao dar "uma olhada inquieta ao redor", parece não encontrar cavalo algum. A procura pelo cavalo, seguida, imediatamente, pelo fim do fragmento, já é o suficiente para deixar a expectativa do leitor em suspenso e à procura de respostas que o texto não forneceu. É possível perguntar: por que o último marido caiu do cavalo? O que ela quis dizer com "caiu"? Ele caiu, literalmente? Se sim, por que o novo pretendente/namorado/marido não encontra cavalo algum para montar? Existe uma conotação sexual em montar?

Os textos são construídos a partir de pontos de indeterminação e o leitor é inserido em um jogo cujo objetivo é preencher silêncios e unir fendas. As perguntas, é claro, são subjetivas, não há determinação precisa para o preenchimento, ainda que não se possa negar o controle primeiro do texto. Assim, as lacunas são possibilidades de o leitor interpretar e dar a sua voz ao texto.

É claro que ocultar detalhes e lançar luz ao leitor não é nenhuma novidade, principalmente com relação ao conto. Hemingway já havia apontado para a omissão de parte da narrativa e Poe demarcou o protagonismo do leitor ao discorrer sobre a unidade de efeito. Contudo, Poe (1997, p. 913) justificou que "certo grau de duração é exigido, absolutamente, para a produção de qualquer efeito", quer dizer, não parecia possível para Poe que uma narrativa extremamente breve pudesse provocar efeitos no leitor. Essa é a grande novidade. É nesse momento que os comentários acerca da brevidade e precisão das mininarrativas podem 
ser compreendidos em sua totalidade. O texto breve intensifica o papel do não dito e envolve o leitor em uma gramática do silêncio, comprovando que "todo texto [inclusive os minicontos] é uma máquina preguiçosa pedindo ao leitor que faça o seu trabalho" (ECO apud SPALDING, 2008, p. 62) - e ainda bem.

Não é possível reconhecer um esforço criativo com relação à brevidade e aos silêncios nos textos de Fitzgerald. Não afirmo que esse esforço não exista, mas sabemos que os textos não passaram por um processo de depuração, ou seja, não foram escritos e reescritos para alcançar a brevidade e a precisão. São fragmentos e, por isso, são breves. De qualquer forma, não posso deixar de notar os efeitos de textos como: "Os dezenove olhos verdes selvagens de um ônibus subindo em sua direção no escuro" (FITZGERALD, 2007, p. 114) ou "Como um masturbador incorrigível, ele estava em geral num estado de repulsa pela vida. Aconteceu, entretanto, etc." (FITZGERALD, 2007, p. 162).

Diante do que foi exposto, creio que a aproximação proposta não só é possível, como praticável. Os textos de Fitzgerald não são apenas fragmentos breves e precisos, como também contemplam pontos caros e bastante discutidos acerca das mininarrativas. Como vimos, os fragmentos podem ser relacionados às noções de "brevedad, diversidad, fractalidad e fugacidade" de Zavala, alguns podem ainda ser lidos à luz das considerações de Gonzaga sobre a unidade mínima narrante e o estabelecimento de lacunas que promovem o protagonismo do leitor durante o processo de leitura (SPALDING, 2008) é, sem dúvida, visível.

Não pretendo dar a discussão como acabada, reconheço a brevidade do trabalho e acredito que os minitextos de Fitzgerald poderiam ser ainda articulados a outras contribuições, como as de Ricardo Piglia, em Formas Breves (1999), e as de David Lagmanovich, no artigo "En el territorio de los microtextos" (2011). Por isso, a discussão realizada aponta para uma proposição, que, mesmo não discutida com exaustão em estudos posteriores, pode, desde já, apontar para novas possibilidades de leitura, como contribuir para que os minitextos de Fitzgerald não sejam encarados apenas como notas ou fragmentos, mas principalmente como pequenas histórias em potência.

\section{Considerações finais}

"Nenhuma ideia grandiosa jamais foi gerada em uma conferência, mas muitas ideias tolas ali morreram" (F. S. Fitzgerald).

Após apresentar um breve panorama sobre a história dos textos breves e articular os fragmentos de Fitzgerald às principais contribuições teóricas acerca do gênero, findo a observação empenhada propondo a aproximação entre os textos do escritor norteamericano e o que hoje compreendemos enquanto mininarrativas, minicontos ou minificção. 
A pretensão, como já esclarecido anteriormente, não é demarcar categoricamente essa relação ou procurar uma classificação para os pequenos textos de Fitzgerald, mas apontar a proximidade como uma possibilidade e, a partir dela, refletir sobre novos caminhos de leitura e análise não só com relação aos fragmentos fitzgeraldianos, como também às mininarrativas. Dessa forma, torna-se possível contar com mais um registro para o considerável acervo de narrativas breves e abordar os cadernos de notas presentes na obra Crack-up a partir de uma outra perspectiva, compreendendo que a "história é construída com o não-dito, com o subentendido e a alusão" (PIGLIA, 2004, p. 92) e que a brevidade nada mais é do que a potência em estado de condensação.

\section{REFERÊNCIAS}

CALVINO, Í. Seis propostas para o próximo milênio. Lições Americanas. 2. ed. Tradução Ivo Barroso. São Paulo: Companhia das Letras, 1997.

CANDIDO, A. A educação pela noite e outros ensaios. 2. ed. São Paulo: Ática, 1989.

CORTÁZAR, J. Alguns aspectos do conto. In: CORTÁZAR, J. Valise de Cronópio. 2. ed. São Paulo: Perspectiva, 1993.

FITZGERALD, F. S. K. Crack-up. Organização e edição de Edmundo Wilson. Tradução Rosaura Eichenberg. Tradução Isis Alvez (poemas). Porto Alegre: L\&PM, 2007.

FREIRE, M. Prefácio. In: FREIRE, M. (org.). Os cem menores contos brasileiros do século. Cotia: Ateliê Editorial, 2004.

GONZAGA, P. A poética da minificção: Dalton Trevisan e as ministórias de Ah, é? 2007. Dissertação (Mestrado em Literatura Brasileira) - Instituto de Letras, Universidade Federal do Rio Grande do Sul, Porto Alegre, 2007.

MORICONI, Í. Prefácio. In: FREIRE, M. (org.). Os cem menores contos brasileiros do século. Cotia: Ateliê Editorial, 2004.

PIGLIA, R. Formas Breves. Tradução José Marques Mariani de Macedo. São Paulo: Companhia das Letras, 2004.

POE, E. A. Filosofia da Composição. In: POE, E. A. Ficção Completa, Poesia \& Ensaios. Rio de Janeiro: Nova Aguilar, 1997.

SCHØLLHAMMER, K. E. Fiç̧ão Brasileira Contemporânea. Rio de Janeiro: Civilização Brasileira, 2009. 
SPALDING, M. Os cem menores contos brasileiros do século e a reinvenção do miniconto na literatura brasileira contemporânea. 2008. Dissertação (Mestrado em Literaturas Brasileira, Portuguesa e Luso-africana) - Instituto de Letras, Universidade Federal do Rio Grande do Sul, Porto Alegre, 2008.

TREVISAN, D. Pico na veia. 2. ed. Rio de Janeiro: Record, 2002.

VIEIRA, M. H. B. Formas Mínimas: minificção e literatura brasileira contemporânea. 2012. Tese (Doutorado em Letras - Estudos Literários) - Centro de Letras e Ciências Humanas, Universidade Estadual de Londrina, Londrina, 2012.

WALDMAN, B. Mínimo múltiplo: do conto do haicai de Dalton Trevisan. Letras - Revista do Mestrado em Letras da UFSM (RS), Santa Maria, n. 14, p. 139-149, jan./jun. 1997.

ZAVALA, L. Minificción Contemporánea La Ficción Ultracorta y la Literatura Posmoderna. 2011. Disponível em: http://www.laurozavala.info/attachments/Notas_Minificcin.pdf. Acesso em: 02 ago. 2020.

ZAVALA, L. Cartografías del cuento y la minificción. Sevilla: Iluminaciones Renacimiento, 2004.

ZAVALA, L. El cuento ultracorto bajo a microscopio. Rlit, Espanha, LXIX, 128, p. 540-553, 2002. 